\title{
TITLE:
}

\section{Lateral position preference in grazing feral horses}

$\operatorname{AUTHOR}(S)$ :

Inoue, Sota; Yamamoto, Shinya; Ringhofer, Monamie; Mendonça, Renata S.; Hirata, Satoshi

\section{CITATION:}

Inoue, Sota ...[et al]. Lateral position preference in grazing feral horses. Ethology 2020, 126(1): 111-119

ISSUE DATE:

2020-01

URL:

http://hdl.handle.net/2433/252839

\section{RIGHT:}

This is the peer reviewed version of the following article: Inoue, S, Yamamoto, S, Ringhofer, M, Mendonça, RS, Hirata, S. Lateral position preference in grazing feral horses. Ethology. 2020; 126: 111- 119, which has been published in final form at https://doi.org/10.1111/eth.12966. This article may be used for non-commercial purposes in accordance with Wiley Terms and Conditions for Use of Self-Archived Versions.; The full-text file will be made open to the public on 4 October 2020 in accordance with publisher's 'Terms and Conditions for Self-Archiving'.; This is not the published version. Please cite only the published version.; この論文は出版社版でありません。引用の際には出版社版をご確認ご利用ください。 
1 Title: Lateral position preference in grazing feral horses

2 Short running title: Spatial lateralisation in feral horses

3

4 Sota Inoue ${ }^{1}$, Shinya Yamamoto ${ }^{2}$, Monamie Ringhofer ${ }^{2}$, Renata S Mendonça ${ }^{3,4}$, Satoshi

$5 \quad$ Hirata $^{1}$

61 Wildlife Research Center, Kyoto University, Kyoto, Japan

72 Institute for Advanced Study, Kyoto University, Japan

83 Primates Research Institute, Kyoto University, Japan

94 Centre for Functional Ecology - Science for People \& the Planet, Department of Life

10 Sciences, University of Coimbra, Coimbra, Portugal

11

12 Correspondence:

13 Sota Inoue

14 Wildlife Research Center, Kyoto University

15 2-24 Tanaka Sekiden-cho, Sakyo, Kyoto 606-3201, Japan 


\section{Acknowledgements}

19 Special thanks to Viana do Castelo city for supporting our project. We are also grateful to

20 Carlos Pereira, Agostinho Costinha, Director of Descubra Minho, and Lourenço Almada

21 of Associação O Caminho do Garrano. We also thank the villagers in Montaria for their

22 support during our stay, Tetsuro Matsuzawa for generous guidance throughout the study.

23 We thank Bronwen Gardner, PhD, from Edanz Group (www.edanzediting.com/ac) for

24 editing a draft of this manuscript.

25

26 


\section{Abstract}

28 Behavioural lateralisation is an effective way for animals to manage daily tasks by

29 specializing behaviour to either side of the body. Many types of lateralisation are linked

30 to the function of each brain hemisphere. Lateralisation of monitoring behaviour in

31 mother-infant relationships occurs in a wide range of mammals, where infants

32 frequently use their left eye to monitor their mother. However, few studies have focused

33 on this type of spatial relationships among adults in daily life, such as during foraging.

34 The present study focused on monitoring adult feral horse behaviour using quantitative

35 analysis of spatial relationships, using drone technology. We found that horses form a

36 localised spatial relationship to their nearest neighbour. Specifically, the nearest

37 neighbour was located to the left rear of a target individual significantly more frequently

38 than to the right rear. Furthermore, the nearest neighbour was less frequently located

39 behind a target individual. We propose that this relationship is caused by a left-eye

40 preference, because information via the left eye predominantly proceeds to the right

41 hemisphere, which is dominant for social processing.

43 Key words: Laterality, spatial positioning, horses, drone 


\section{Introduction}

46 Many animals demonstrate various types of laterality. There is functional and

47 morphological asymmetry between the left and the right brain hemispheres (Bisazza,

48 Rogers, \& Vallortigara 1998; Halpern, 2005; LeMay, 1976; Levy, 1977; Lindell, 2013),

49 and this asymmetry corresponds to several types of behavioural laterality. Many studies

50 have supported the right hemisphere theory, where the right hemisphere is superior for

51 social processing (Brancucci, Lucci, Mazzatenta, \& Tommasi, 2009; Jackson, 1915;

52 Okubo, Ishikawa, \& Kobayashi, 2013). This superiority is considered to be related to the

53 dominance of the left eye in the perception of social stimuli (Brancucci et al., 2009).

54 Specifically, monitoring conspecifics using the left eye/right hemisphere provides

55 advantages including better facial expression detection, increased frequency of positive

56 interactions that strengthen inter-individual relationships, more aggression during agonistic behaviour, and quicker reactions to movement by conspecifics and predators

58 (Austin \& Rogers, 2012, 2014; Karenina, Giljov, Ingram, Rowntree, \& Malashichev,

59 2017; Nagy, Ákos, Biro, \& Vicsek, 2010). Most previous reports focusing on the laterality

60 of social interactions have investigated interactions in a counter-directed position, where 
61 individuals face each other, and findings include the left-cradling bias in mother-infant

62 relationships in humans and great apes (Giljov, Karenina, \& Malashichev, 2018; Harris,

63 2010; Sieratzki \& Woll, 1996). In species that have a relatively large binocular field of

64 view, mothers hold their infants on the left side of the body in a counter-directed position,

65 so that both are in an optimal position to monitor each other because both can use optimal

66 information flow. The left-cradling bias in mother-infant relationships has recently been

67 expanded to a diverse range of mammals, especially in species moving in codirected

68 positions, where individuals are side-by-side on parallel paths. For example, offspring of

69 the feral horse, Pacific walrus, Siberian tundra reindeer, saiga antelope, muskox, eastern

70 grey kangaroo, red kangaroo, sheep, orca, and beluga whale are more often on the right

71 side of their mothers than on the left (Giljov et al., 2018; Karenina, Giljov, Glazov, \&

72 Malashichev, 2013; Karenina et al., 2017; Karenina, Giljov, Ivkovich, Burdin, \&

73 Malashichev, 2013; Versace, Morgante, Pulina, \& Vallortigara, 2007). Researchers

74 consider that infants take the initiative in positioning in situations such as rest or slow

75 movement, and prefer to view their mothers using the left eye. This consistency in

76 laterality among mammals implies an ancient evolutionary origin of this bias. However, 
77 it remains unknown whether the bias is limited to mother-infant relationships. If using the

78 left eye field of view works well in mother-infant relationships, we might expect that this

79 type of position bias also occurs between adults that live in groups, because adults also

80 need to adjust their distance and positioning relative to other individuals to maintain

81 group cohesion. To investigate whether lateral bias exists in spatial positioning among

82 adult animals, we analysed data from adult feral horses. Feral horses usually form long-

83 term stable groups (Berger, 1977) and do not frequently face each other in foraging

84 situations, although mutual grooming and mutual swatting of flies are performed in

85 counter-directed positions (i.e., two individuals facing opposite directions) (Feist,

86 Mccullough, \& Dean, 1976; Heleski, Shelle, Nielsen, \& Zanella, 2002). Horses are a good

87 species for studying behavioural lateralisation because they have a relatively small field

88 of binocular vision, estimated at $80^{\circ}$, and their left and right eyes have largely independent

89 views of their left and right sides, respectively (Harman, Moore, Hoskins, \& Keller, 1999).

90 Several studies have reported laterality in behaviours including agonistic and affiliative

91 behaviours in counter-directed positions, vigilance to auditory stimuli, and relative spatial

92 positioning in mother-infant relationships in horses in co-directed positions (i.e., two 
93 individuals facing the same direction) (Austin \& Rogers, 2012, 2014; Farmer, Krueger,

94 \& Byrne, 2010; Farmer, Krüger, Byrne, \& Marr, 2018; Karenina et al., 2017; Karenina,

95 Giljov, \& Malashichev, 2018). According to previous studies, horses frequently use their

96 left eyes during these behaviours, similar to other species. Specifically, horses have a left-

97 eye preference for monitoring novel stimuli, and a left-body preference for threatening

98 and attacking within harem bands and for positive social interactions in mother-infant

99 relationships (Austin \& Rogers, 2014; Karenina et al., 2017; Larose, Richard-Yris,

100 Hausberger, \& Rogers, 2006). Thus, functional lateralisation is not limited to infancy but

101 continues throughout adulthood. We therefore hypothesised that this left-eye bias in

102 monitoring conspecifics also occurs in adult-adult spatial positioning, although we did

103 not have a detailed specific hypothesis as to which way such a lateral bias might appear

104 in spatial positioning; as such, our study was exploratory in nature. The present study

105 aimed to address the question of whether previously observed lateral preferences are

106 reflected in the positioning of adult horses while grazing, and if so, which side is preferred. 
109 In the present study, we analysed images taken from drones, which allowed us to test

110 whether there was any lateral bias in spatial positioning in adult horses during foraging,

111 with a focus on the position of a target horse and its nearest neighbouring individual.

113 northern Portugal $\left(8^{\circ} 42^{\prime} \mathrm{N}, 41^{\circ} 48^{\prime} \mathrm{E}\right)$. The horses' habitat included a grass field, rocky

114 ground, a forest, and shrub areas (Ringhofer et al., 2017) (Appendix 1). Over 250

115 identified feral horses, categorised as Garrano horses, lived in the site. They roamed freely

116 over the mountain living on the natural grazing and water resources. There were no

117 artificial barriers to impede their movement, they did not have daily human contact, and

118 they were not fed by humans. Horses form long-term stable harems and unstable bachelor

119 groups, and we focused on two harems in June 2016, May-July 2017, and May-July 2018.

120 We chose the two groups because it was relatively easy to find these groups compared

121 with other groups. Both were one-male harems. We followed 10 individuals in 2016, 19

122 individuals in 2017, and 11 individuals in 2018. Kameoka, in Kyoto 17, was one year old,

123 and was an immature male and, not the stallion (Appendix 2). In 2017, Kyoto and Hyogo

124 were constantly together and kept a close distance between one another; there were 
125 therefore cases in which the nearest neighbour of an individual was a horse from the other

126 group. Eight horses were less than 1 year old and these individuals were excluded from

127 the analysis due to their high dependency on their mothers, because the aim of the present

128 study was to analyse adult individuals. For the same reason, data from the mothers of

129 these foals were also excluded from the analysis. Although seven foals died before 1 year

130 of age, one foal survived beyond 1 year and the individual was included in the analysis

131 from this point on. In sum, 5 individuals in 2016, 11 individuals in 2017, and 7 individuals

132 in 2018 contributed to the data.

The recordings involved 4-13 (average 6.7) video clips per day and these were

134 taken between 9:00 and 18:00. Video clips were taken for approximately 15 min every 30

135 min, from 25-80 m above the ground (the heights were decided on a case-by-case basis

136 to be able to include all target group individuals in one image) using unmanned aerial

137 vehicles (drones). Still images were obtained by taking images from the video clips after

$1381 \mathrm{~min}$ from the beginning of the clips (i.e., there was 30 min between two consecutive

139 still images). The distortion of the camera lens was corrected using the lens filter function

140 in Photoshop CC (Adobe Systems incorporated) (Inoue et al., 2018). The drone took off 
$141 \quad 10-50 \mathrm{~m}$ away from the horses. The drones used for collecting data were the Phantom 3

142 Advanced, Phantom 3 Professional, and Mavic Pro (DJI, China). Behavioural observation

143 was performed by SI during flights to estimate group states. We defined the states as

144 foraging, traveling, and resting, and only analysed data during foraging because horses

145 change their spatial positioning formation depending on their state (Inoue et al., 2018).

146 After excluding images of horses in the resting or traveling states, 184 images were

147 analysed. All harem group members were recorded and clearly visible in each of the 184

148 images (Appendix 1). We measured an individual's coordinates as a central point between the head

150 and the base of the tail and defined an individual's direction as a vector from the base of

151 the tail to the base of the neck; the magnitude of the vector was defined as the body length.

152 Mean body length of adult horses was used as a unit of distance, because it is relatively

153 stable and fixed (Appendix 1). Using individuals' coordinates in each image, nearest

154 neighbours were determined for each individual. When the distance to the nearest

155 neighbour was more than two body lengths, data were excluded from the analysis

156 according to previous studies (Karenina et al., 2017; Inoue et al., 2018). To analyse spatial 
157 relationships among adults only, we excluded mothers and foals from the analysis.

158 Although it is known that proximity between individuals is related to their social bonds,

159 our analysis did not rely on just a few pairs (Appendix 3) (Kimura, 1998; Schneider \&

160 Krueger, 2012; Wolter, Stefanski, \& Krueger, 2018). A total of 308 points were analysed

161 to quantify relative positioning.

162 Circular variance was calculated to analyse the degree of variance in body

163 direction of individuals $\left(C V_{d}\right)$ :

164

$$
C V_{d}=1-\frac{1}{N} \sum_{i}\left|\vec{v}_{d i}\right|
$$

165 where $N$ is the number of vectors $\vec{v}_{d i}$, and $\vec{v}_{d i}$ indicates a unit vector of the direction of

166 individual $i$ (Appendix 4). If all individuals face the same direction, $C V_{d}=0$, whereas if

167 they face completely random directions, $C V_{d}=1$. Circular variance among individuals'

168 positions $(C V p)$ was calculated from the same formula:

$$
C V_{p}=1-\frac{1}{N} \sum_{i}\left|\vec{v}_{p i}\right|
$$

170 where $\vec{v}_{p i}$ indicates a unit vector from the central point of an individual to the central

171 point of their nearest neighbour $i$ (Appendix 4). A Rayleigh test was used to investigate

172 whether the population of circular data from which a sample was drawn differed from 
173 randomness, by comparing the sum of random vectors and the sum of observed vectors

174 (Wilkie, 1983).

175 To further analyse the spatial positions of nearest neighbours, we created a two-

176 body-length-diameter circular area surrounding a target individual and divided it into 24

177 zones with an angle of $15^{\circ}$ per zone. The front direction of a target individual was set as

$1780^{\circ}\left(\right.$ or $\left.360^{\circ}\right)$, and the angle was defined in a counterclockwise direction. Each zone had a

$17915^{\circ}$ range $\left(0^{\circ}-15^{\circ}, 15^{\circ}-30^{\circ}\right.$, etc.; the left of a target individual was $90^{\circ}$, the back $180^{\circ}$,

180 and the right $270^{\circ}$ ). G-tests and residual analyses were run to examine the frequency at

181 which the nearest neighbour was located in each of these 24 zones compared with the

182 expected value. To investigate whether the overall trend came from just a few pairs, we

183 computed the laterality index (LI) in all observed pairs as follows: $L I=L /(L+R)$, where

$184 L$ indicates the frequency of the nearest neighbour being located on the left side of the

185 target individual and $R$ indicates the frequency for the right side. We computed the LI of

186 the rear individual in reference to the front individual because (1) if we calculated the LI of a pair of individuals, A and B, by counting both the sides (left or right) of A in reference 
189 individual needed to be fixed to one of the two individuals; and (2) the overall result

190 (described in the Results section) showed that the position of the nearest neighbour was

191 biased to the left-rear compared with the right-rear, and so we were interested to see if the

192 same trend could be seen in a pair-by-pair comparison, or if a certain pair contributed to

193 the overall results. Circular analyses and all statistical analyses were performed using

194 “Circular” package (Pocernich \& Agostinelli, 2017), R 3.3.2 and RStudio (V1.1.447,

195 Rstudio, Inc.).

196

197 3. Results

198 For nearest neighbours within two body lengths, circular variance among directions was

199 0.52, which means that the distribution differed from uniform distribution, but that the

200 horses faced the same direction ( $p<0.01$, Rayleigh test; Appendix 5). Excluding mothers

201 and foals, density maps of nearest neighbours showed clear trends of locations that

202 significantly differed from uniform distribution (Figure 1; $n=308, p<0.01$, Rayleigh

203 test). Nearest neighbours were significantly more likely to be located in the left rear area

204 than in the right rear area $(n=130, p=0.021$, binomial test), but a trend for increased 
205 frequency in the right front area compared with the left front area was not significant (n

$206=178, p=0.30$, binomial test). These data came from a total of 45 pairs, and among these

207 pairs, 26 pairs showed bias to the left rear compared with right rear (i.e., LI > 0.5), 12

208 pairs showed bias to the right rear $(\mathrm{LI}<0.5)$, and the remaining 7 pairs did not show side

209 bias (LI = 0.5; Appendix 3). When the surrounding area of an individual was divided into

$21015^{\circ}$ zones, there was non-uniform frequency in the zone of the nearest neighbour (G-test,

$211 G=40.641, d f=23, p=0.01)$. Residual analyses showed that the frequency of the nearest

212 neighbour in the $180^{\circ}-195^{\circ}$ zones was significantly lower than in other zones, while the

213 frequency of the nearest neighbour in the $120^{\circ}-135^{\circ}$ zones was significantly higher

214 (Table 1, Figure 2). Circular variance of vectors of an individual and its nearest neighbour

215 were 0.10 in the right front area and 0.086 in the left rear area (Figure 2).

216

217 4. Discussion

218 Our results were threefold. Firstly, the nearest neighbour was located to the left

219 rear of a target individual significantly more frequently than to the right rear. Secondly, 
221 frequently than to the left front, although this trend was not significant. Thirdly, the

222

223

225

226 the front individual when the rear individual approaches the front individual. Given that

227 the nearest neighbour is located more often in left-rear of a target individual, this first

228 scenario would indicate that the rear individual has a preference to use its right eye to

229 monitor the front individual at its right front.

230

231 the initiative in positioning when it is approached by an individual from behind. When an

232 individual approaches another individual from behind, the front animal changes its

233 direction to avoid a situation where the other individual is located in its blind spot (i.e.,

234 behind the target individual). The front individual then turns its body to see the rear individual using its left eye, resulting in the nearest neighbour (the rear individual) being

In contrast, the second possible scenario assumes that the front individual has

(n)


238 be expected to appear more strongly when monocular vision is used than when binocular

239 vision can be used. When a rear individual approaches a front individual, the rear

240 individual can use binocular vision to see the front individual. However, when a front

241 individual attempts to see a rear individual, the front individual can use only monocular

242 vision (either the left eye or the right eye) by turning left or right. Because information

243 via the left eye, which predominantly proceeds to the right brain hemisphere, is dominant

244 in perceiving social stimuli, the front individual may then tend to turn its body to see the

245 rear individual using its left eye. This may explain why the nearest neighbour was less

246 frequently located behind the target individual, and was more frequently located in the

247 left rear than in the right rear.

A further interpretation is that, when individual $\mathrm{A}$ is the nearest neighbour of a

249 target individual $\mathrm{B}$, then individual $\mathrm{B}$ is also likely to be the nearest neighbour of

250 individual A. Therefore, if the nearest neighbour of a target individual is more frequently

251 located in the left rear of the individual, then the nearest neighbour of the latter individual

252 would be located in the right front, assuming that the two individuals' head directions are 
253 similar. This is consistent with our results, where the nearest neighbour tended to be

254 located in the right front rather than the left front. However, the head direction of the rear

255 individual is not always the same as that of the front individual and can vary (the rear

256 individual could approach the front individual from the right or left, because the rear

257 individual can use both eyes to monitor the front individual). Therefore, any trend in the

258 nearest neighbour's location would be expected to be weak due to variation in head

259 direction of the rear individual. This is also consistent with our finding that there was no

260 significant lateralisation of the nearest neighbour in the front of individuals.

To verify our results and interpretation, a sequential analysis of the change in

262 head direction of a front individual when it is approached from behind, toward the blind

263 spot, is warranted. Recordings of movements of a target and its nearest neighbour would

264 reveal which of these two has the initiative to decide positioning, and whether the

265 individual with the initiative has a preference to see conspecifics using its left or right eye.

266 The very short battery life of drones (approximately 15-20 min) is the most prominent

267 challenge to conducting a sequential analysis, and we could therefore not conduct such a

268 study. We expect that future advancement in technology will solve this challenge. 
among adult feral horses during foraging. Previous studies reported that the left eye and

\section{1} right hemisphere are frequently used during agonistic and affiliative behaviours in horses and other species (Austin \& Rogers, 2012, 2014; Deckel, 1995; Farmer et al., 2018;

273 Garbanati et al., 1983). In addition, offspring of various mammal species tend to monitor

274 their mother using their left eye (Karenina et al., 2017). Our study illustrates that spatial

275 positioning bias is not restricted to mother-infant relationships, but can also be seen

276 between adults. However, we did not investigate developmental change with aging in the

277 present study and further research is needed to understand how this bias might change

278 with age. In addition, our research site was characterised by the presence of wolves, which

279 are predators of horses, and a future direction to be studied would thus include the

280 possibility that horses might use different eyes to detect conspecifics and predators.

281 Further quantitative studies using drones to investigate relationships between spatial

282 positioning and social variables, including sex and social rank, will provide new insight

283 into the effect of social relationships on spatial distributions, from local aspect to global

284 views; that is, from nearest neighbours to the whole group. In conclusion, technological 
285 developments have allowed us to investigate the spatial relationships of terrestrial animals

286 in detail, and future advances may reveal the underlying mechanisms of these

287 relationships, which could lead to a better understanding of the evolutionary foundations

288 of human behaviour (Torney et al., 2018; Westley, Berdahl, Torney, \& Biro, 2018)

289

290 


\section{Author contributions}

293 S.I. configured the study and collected and analysed data. M.R. and R.M. identified horses

294 and their groups. All authors contributed to the manuscript and approved the final version.

295

296

297 Competing interests

298 We declare no competing interests.

299

$300 \quad$ Ethical Statement

301 The field observations complied with guidelines for animal studies in the wild issued by

302 the Wildlife Research Center of Kyoto University, Japan.

303

304

305 
306 Table 1 Residual analyses following a G-test for the frequency of nearest neighbours 307 within each zone.

308

\begin{tabular}{|c|c|c|}
\hline Zone (Degree) & Frequency & $P$-value \\
\hline 0-15 & 13 & 0.96 \\
\hline $15-30$ & 17 & 0.23 \\
\hline $30-45$ & 13 & 0.96 \\
\hline $45-60$ & 17 & 0.23 \\
\hline $60-75$ & 11 & 0.60 \\
\hline $75-90$ & 14 & 0.74 \\
\hline 90-105 & 11 & 0.60 \\
\hline $105-120$ & 12 & 0.81 \\
\hline 120-135 & 22 & $0.0090 *$ \\
\hline $135-150$ & 9 & 0.27 \\
\hline $150-165$ & 11 & 0.60 \\
\hline $165-180$ & 11 & 0.60 \\
\hline 180-195 & 3 & $0.0050 *$ \\
\hline $195-210$ & 6 & 0.051 \\
\hline 210-225 & 6 & 0.051 \\
\hline $225-240$ & 10 & 0.42 \\
\hline $240-255$ & 13 & 0.96 \\
\hline $255-270$ & 16 & 0.37 \\
\hline 270-285 & 17 & 0.23 \\
\hline $285-300$ & 19 & 0.079 \\
\hline $300-315$ & 18 & 0.14 \\
\hline $315-330$ & 16 & 0.37 \\
\hline $330-345$ & 8 & 0.17 \\
\hline $345-360$ & 15 & 0.54 \\
\hline
\end{tabular}

* indicates $p<0.05$ 


\section{Figure}

312

\section{$313 \quad$ Figure 1}

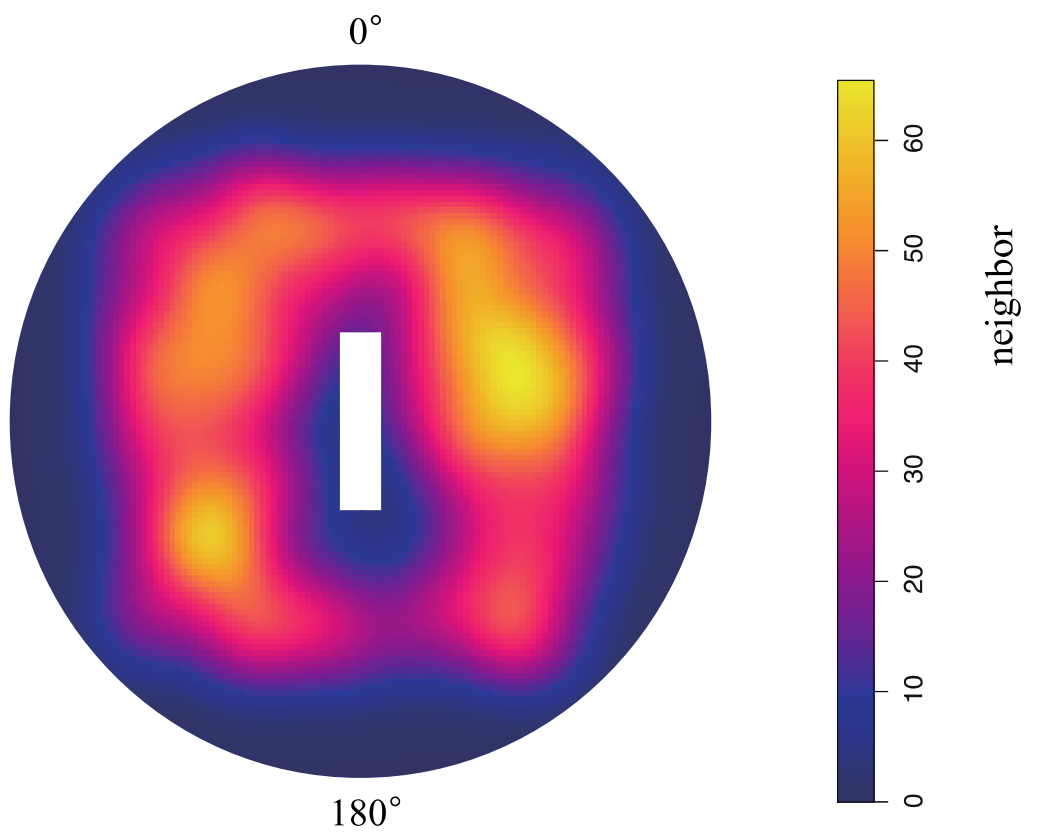

315 Heat map showing the density of nearest neighbours within two body lengths (BL) around

316 an individual. In total, 308 points were used to create this map and bin sizes were $\Delta x=\Delta y$

$317=0.67 \mathrm{BL}$; there were 17 points per square unit. 
319 Figure 2

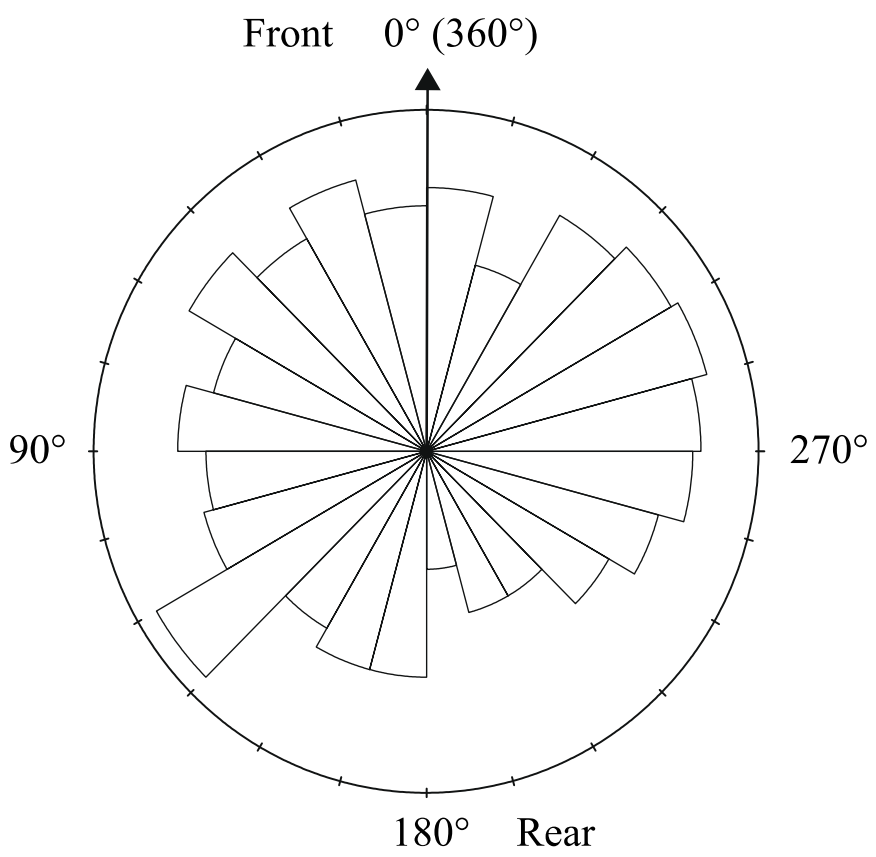

321 Rose diagram of the positioning of nearest neighbours $(n=308)$. Each bar's height

322 represents the frequency of nearest neighbours in each zone. Circular variance was

323 higher in the right and front zones compared with the left and rear zones. 


\section{References}

326 Angelo Bisazza, L. J. Rogers. and G. Vallortigara. (1998). The Origins of Cerebral

Austin, N. P., \& Rogers, L. J. (2012). Limb preferences and lateralization of aggression, reactivity and vigilance in feral horses, Equus caballus. Animal Behaviour, 83(1), 239-247. https://doi.org/10.1016/j.anbehav.2011.10.033

Austin, N. P., \& Rogers, L. J. (2014). Lateralization of agonistic and vigilance responses in Przewalski horses (Equus przewalskii). Applied Animal Behaviour Science, 151, 43-50. https://doi.org/10.1016/j.applanim.2013.11.011

Berger, J. (1977). Organizational systems and dominance in feral horses in the Grand Canyon. Behavioral Ecology and Sociobiology, 2(2), 131-146. https://doi.org/10.1007/BF00361898 
343 Deckel, A. W. (1995). Laterality of Aggressive Responses in Anolis, 200, 194-200.

344 Farmer, K., Krueger, K., \& Byrne, R. W. (2010). Visual laterality in the domestic horse

345 (Equus caballus) interacting with humans. Animal Cognition, 13(2), 229-238.

346 https://doi.org/10.1007/s10071-009-0260-x

347 Farmer, K., Krüger, K., Byrne, R. W., \& Marr, I. (2018). Sensory laterality in affiliative interactions in domestic horses and ponies (Equus caballus). Animal Cognition, 21(5), 631-637. https://doi.org/10.1007/s10071-018-1196-9

350 Feist, D., Mccullough, R., \& Dean, J. (1976). Behavior patterns and communication in feral horses population, with the exception of completion of a range boundary fence. Ethology, 371(4), 337-371. https://doi.org/10.1111/j.14390310.1976.tb00947.x

354 Garbanati, J. A., Sherman, G. F., Rosen G. D., Hofmann M., Yutzey, D. A., Denenberg, 355 V. H. (1983). Handling in infancy, brain laterality and muricide in rats. Behavioural Brain Research, 7, 351-359.

357 Giljov, A., Karenina, K., \& Malashichev, Y. (2018). Facing each other: Mammal 
mothers and infants prefer the position favouring right hemisphere processing.

363 Harman, A. M., Moore, S., Hoskins, R., \& Keller, P. (1999). Horse vision and an explanation for the visual behaviour originally explained by the "ramp retina." Equine Veterinary Journal, 31(5), 384-390. https://doi.org/10.1111/j.20423306.1999.tb03837.x and possible lessons for today. Laterality (Vol. 15). https://doi.org/10.1080/13576500802584371

370 Heleski, C. R., Shelle, A. C., Nielsen, B. D., \& Zanella, A. J. (2002). Influence of housing on weanling horse behavior and subsequent welfare, 78 .

372 Jackson H. (1915). On the nature of the duality of the brain. Brain, 38(1-2), 80-86. 
374 Karenina, K., Giljov, A., Glazov, D., \& Malashichev, Y. (2013). Social laterality in wild beluga whale infants: Comparisons between locations, escort conditions, and ages. Behavioral Ecology and Sociobiology, 67(7), 1195-1204. https://doi.org/10.1007/s00265-013-1545-2

Karenina, K., Giljov, A., Ingram, J., Rowntree, V. J., \& Malashichev, Y. (2017). Lateralization of mother-infant interactions in a diverse range of mammal species. Nature Ecology and Evolution, 1(2). https://doi.org/10.1038/s41559-016-0030 Lateralization of spatial relationships between wild mother and infant orcas, Orcinus orca. Animal Behaviour, 86(6), 1225-1231. https://doi.org/10.1016/j.anbehav.2013.09.025 interactions in wild horses. Behavioural Processes, 148(November 2017), 49-55. https://doi.org/10.1016/j.beproc.2018.01.010 
390 Larose, C., Richard-Yris, M. A., Hausberger, M., \& Rogers, L. J. (2006). Laterality of horses associated with emotionality in novel situations. Laterality, 11(4), 355-367.

LeMay, M. (1976). Morphological Cerebral Asymmetries of Modern Man, Fossil Man, and Nonhuman Primate. Annals of the New York Academy of Sciences, 280(1 Origins and E), 349-366. https://doi.org/10.1111/j.1749-6632.1976.tb25499.x

395 Levy, J. (1977). the Mammalian Brain and the Adaptive Advantage of Cerebral https://doi.org/10.1111/j.1749-6632.1977.tb41913.x

Lindell, A. K. (2013). Continuities in Emotion Lateralization in Human and NonHuman Primates. Frontiers in Human Neuroscience, 7(August), 1-9. https://doi.org/10.1016/j.neuron.2014.08.058 pigeon flocks. Nature, 464(7290), 890-893. https://doi.org/10.1038/nature08891 
406 Pocernich, M., \& Agostinelli, M. C. (2017). Package ' circular .'

407 Ringhofer, M., Inoue, S., Mendonça, R. S., Pereira, C., Matsuzawa, T., Hirata, S., \&

408 Yamamoto, S. (2017). Comparison of the social systems of primates and feral

409 horses: data from a newly established horse research site on Serra D’Arga, northern Portugal. Primates, 58(4), 479-484. https://doi.org/10.1007/s10329-0170614-y

412 Schneider, G., \& Krueger, K. (2012). Third-party interventions keep social partners from exchanging affiliative interactions with others. Animal behaviour, 83(2), 377387.

415 Sieratzki J.S., \& Woll B. (1996). Why do mothers carry babies on their left. Advances in Child Development and Behavior, 1746-1748. https://doi.org/10.1103/PhysRevLett.87.133603

418 Inoue S., Yamamoto S., Ringhofer M., Mendonça R. S., Pereira C. \& Hirata S. (2018).

419 Spatial positioning of individuals in a group of feral horses : a case study using drone technology, $e$. 
M. (2018). Inferring the rules of social interaction in migrating caribou.

423

Philosophical Transactions of the Royal Society B: Biological Sciences,

424 373(1746). https://doi.org/10.1098/rstb.2017.0385

425

Versace, E., Morgante, M., Pulina, G., \& Vallortigara, G. (2007). Behavioural

426 lateralization in sheep (Ovis aries). Behavioural Brain Research, 184(1), 72-80.

427 https://doi.org/10.1016/j.bbr.2007.06.016

428

Wolter, R., Stefanski, V., \& Krueger, K. (2018). Parameters for the Analysis of Social

429 Bonds in Horses. Animals, 8(11), 191.

430

Westley, P. A. H., Berdahl, A. M., Torney, C. J., \& Biro, D. (2018). Collective

431 movement in ecology: From emerging technologies to conservation and

432 management. Philosophical Transactions of the Royal Society B: Biological

433 Sciences, 373(1746). https://doi.org/10.1098/rstb.2017.0004

434

Wilkie, D. (1983). Rayleigh test for randomness of circular data. In Applied statistics.

435

436 


\section{Appendix 1}
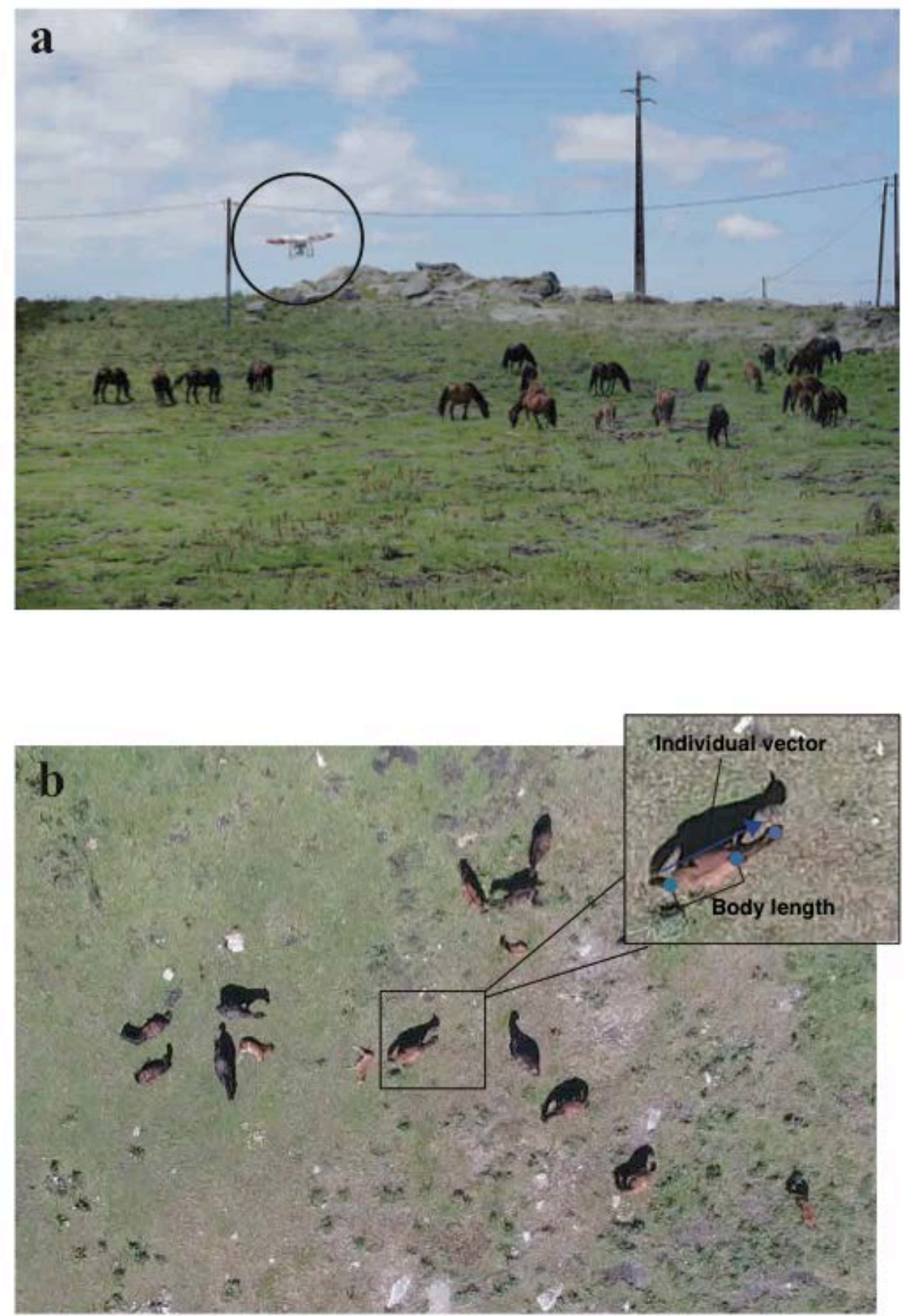

439 (a) Feral horses and the drone (circled in the figure) soon after take-off in Serra D’Arga. 
440 (b) An example of images that were taken by the drone and used for analysis. An

441 individual's vector was defined as a vector from the base of the tail to the base of the

442 neck. Body length of an individual was defined as the magnitude of the individual's

443 vector, because this region was relatively inflexible and stable. Mean body length of all

444 adult individuals in one image was used as the unit of measurement for distance.

445 Because the absolute height of the drone was not consistent, we needed to use relative

446 distance to measure distances. We only used images that contained all group members.

447 Therefore, mean body length was always constant and was used as the unit of

448 measurement for distance.

449

$450 \quad$ Appendix 2

451

\begin{tabular}{cccccccc}
\multicolumn{2}{c}{ Kyoto 2016} & \multicolumn{2}{c}{ Kyoto 2017 } & Hyogo 2017 & \multicolumn{2}{c}{ Hyogo 2018 } \\
\hline Name & Sex & Name & Sex & Name & Sex & Name & Sex \\
\hline Uzumasa & Male & Uzumasa & Male & Kobe & Male & Kobe & Male \\
Akashi & Female & Ayabe & Female & Akashi & Female & Akashi & Female \\
& & & & & & & \\
Ayabe & Female & Fushimi & Female & Himeji & Female & Fushimi & Female
\end{tabular}




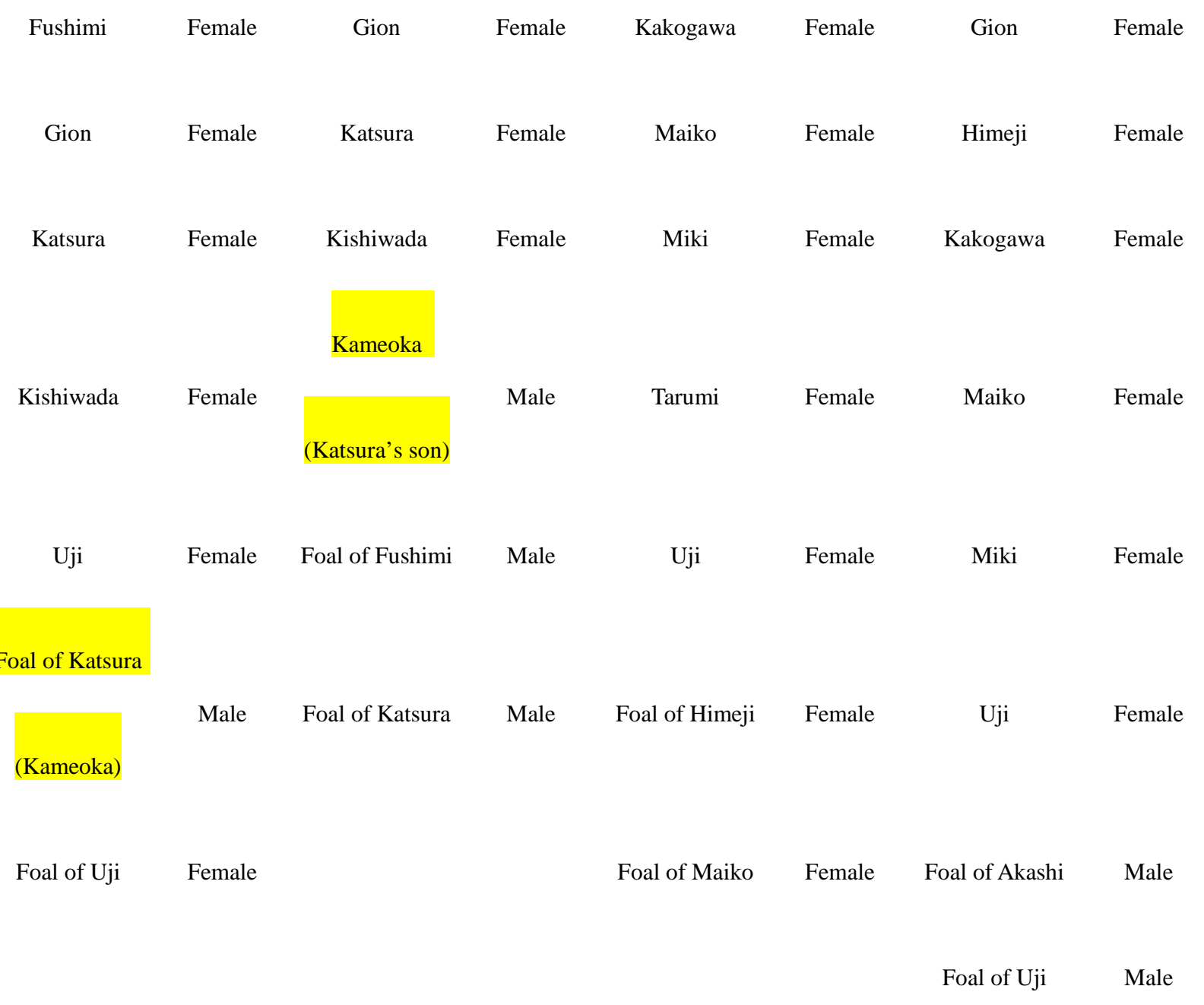

\section{Appendix 3}

455

456 Ratio of lateral positioning of the nearest neighbor located in the rear area in all observed pairs.

457 LI indicates the Laterality Index, computed as $L I=L /(L+R)$, where $L$ is the frequency of the

458 nearest neighbor in the left rear area of the target individual, and $\mathrm{R}$ is the frequency of the nearest

459 neighbor in the right rear area.

460

\begin{tabular}{llccc}
2016 & & & & \\
\hline Name & Name & L & R & LI \\
\hline Ayabe & Fushimi & 2 & 0 & 1.00
\end{tabular}

$\begin{array}{llll}\text { Tarumi } & \text { Uji } & 0 & 3 \\ \text { Uji } & \text { Miki } & 1 & 0 \\ \text { Uzumasa } & \text { Gion } & 1 & 0\end{array}$




$\begin{array}{lllll}\text { Ayabe } & \text { Gion } & 2 & 0 & 1.00 \\ \text { Fushimi } & \text { Ayabe } & 1 & 0 & 1.00 \\ \text { Gion } & \text { Fushimi } & 1 & 0 & 1.00 \\ \text { Kishiwada } & \text { Gion } & 1 & 0 & 1.00\end{array}$

2017

$\begin{array}{lllll}\text { Akashi } & \text { Kakogawa } & 1 & 0 & 1.00\end{array}$

Akashi

Miki

Akashi

Uji

Ayabe

Kameoka

Ayabe

Kishiwada

Gion

Gion

Gion

Kakogawa

Kakogawa

Kakogawa

Kameoka

Kameoka

Kameoka

Kobe

Miki

Tarumi

$\begin{array}{llll}\text { Kameoka } & 2 & 0 & 1.00\end{array}$

Kishiwada

Uji

Kobe

Miki

Uji

Kishiwada

Miki

Uzumasa

Tarumi

Kobe

Miki $\begin{array}{lll}6 & 1 & 0.86\end{array}$

$\begin{array}{lll}5 & 2 & 0.71\end{array}$

$\begin{array}{lll}1 & 0 & 1.00\end{array}$

$\begin{array}{lll}4 & 2 & 0.67\end{array}$

$\begin{array}{lll}1 & 1 & 0.50\end{array}$

$\begin{array}{lll}2 & 2 & 0.50\end{array}$

$\begin{array}{lll}1 & 0 & 1.00\end{array}$

101.00

$\begin{array}{lll}2 & 4 & 0.33\end{array}$

$\begin{array}{lll}0 & 2 & 0.00\end{array}$

$\begin{array}{lll}2 & 0 & 1.00\end{array}$

$1 \quad 0 \quad 1.00$

$\begin{array}{lll}0 & 1 & 0.00\end{array}$

$\begin{array}{lll}1 & 1 & 0.50\end{array}$

$\begin{array}{lll}0 & 1 & 0.00\end{array}$
Uzumas 2018

\begin{tabular}{llccc}
\hline Name & Name & L & R & LI \\
\hline Fushimi & Gion & 3 & 1 & 0.75
\end{tabular}

Fushimi

Himeji

20

1.00

Fushimi

Kakogawa

22

0.50

Fushimi

Maiko

21

0.67

Fushimi Miki

Gion

Himeji

Gion

Kakogawa

42

0.67

Gion

Kobe

Gion

Miki

Himeji

Maiko

Himeji

Kakogawa

Miki

Kobe

Kobe

Kobe

Kobe

Maiko

Maiko

Miki

21

0.67

0.33

0.50

0.75

000

$\begin{array}{lll}0 & 3 & 0.00\end{array}$

$\begin{array}{lll}3 & 7 & 0.30\end{array}$

$\begin{array}{lll}3 & 1 & 0.75\end{array}$

$\begin{array}{lll}2 & 0 & 1.00\end{array}$

Maiko

Himeji

Kakogawa

Maiko

Miki

Gion

Miki

Kakogawa
461

462

\section{Appendix 4}




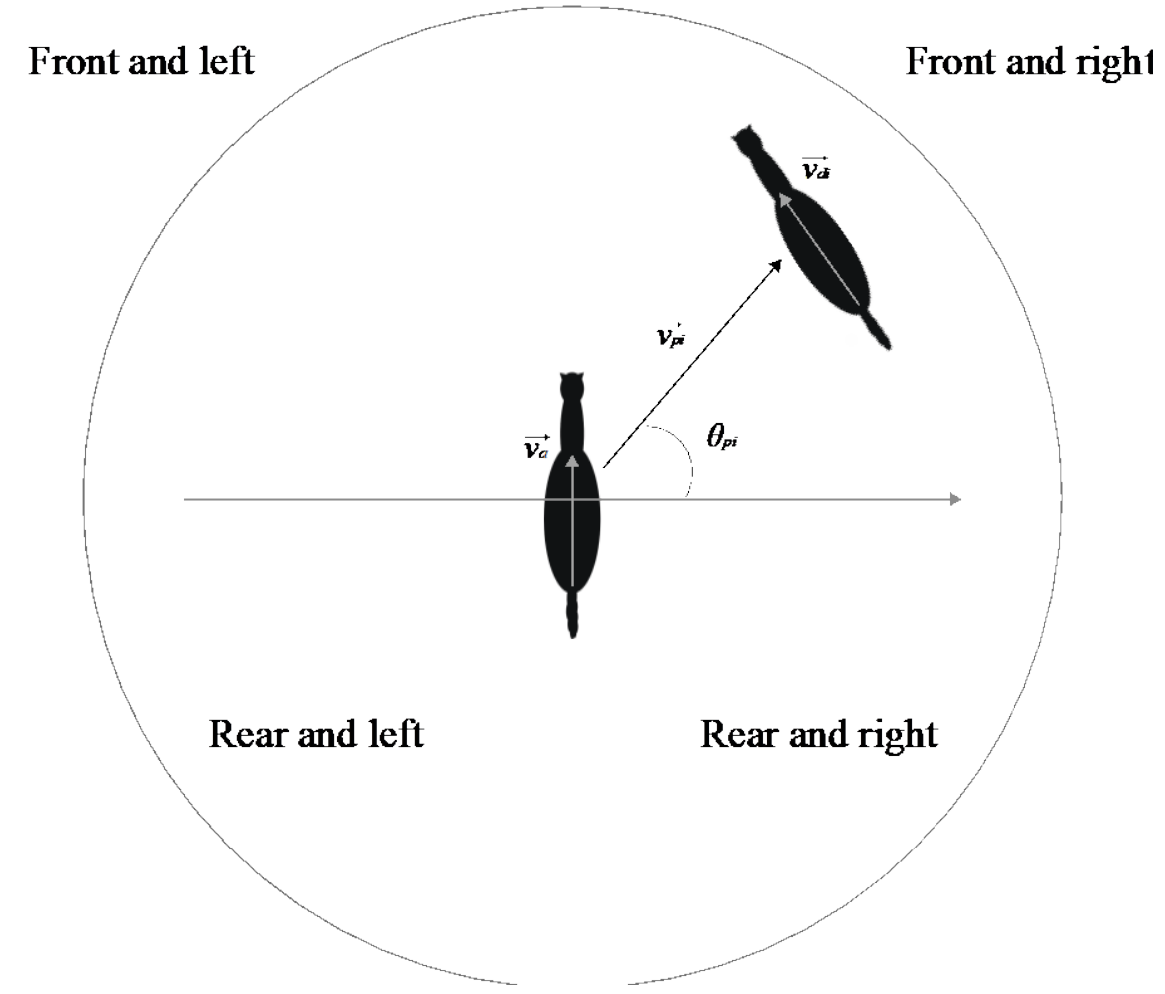

465 Relationships among vectors used in the analysis of circular variance, and definitions of

466 each zone in the rear area of the target individual. We defined quadrants as the front and

467 right, rear and right, rear and left, and front and left areas.

468

469 Appendix 5 


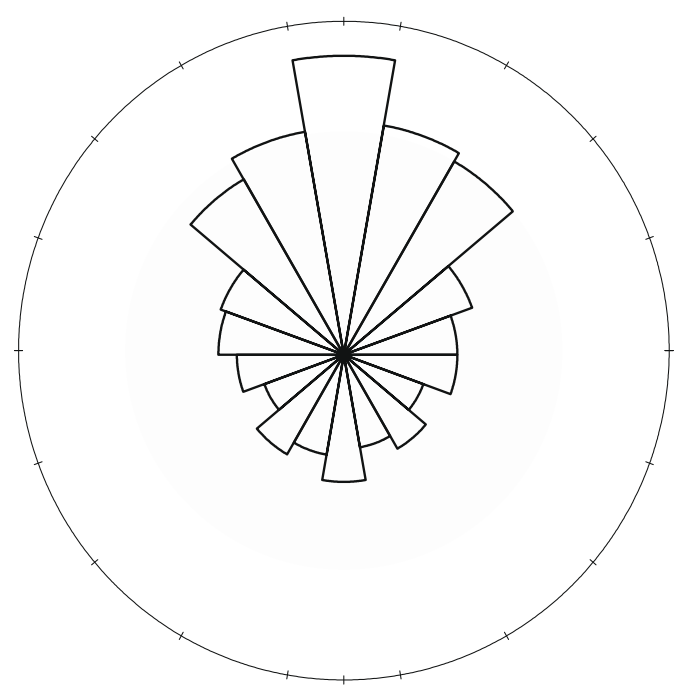

470

471 The histogram of the directions of nearest neighbours within two body lengths, with 0

472 being the same direction as the target individual.

473

474

475 